$$
\begin{aligned}
& \text { مقايسه وضعيت بدنى زنان تكواندوكار نخبه با غيرورزشكاران } \\
& \text { مهسا حكيمى يور '*، روشنك اير اندوست'؛ هومن مينونزاد، رضا رجبى }
\end{aligned}
$$

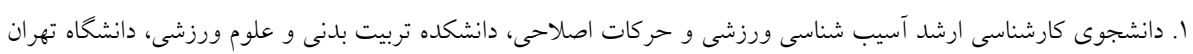

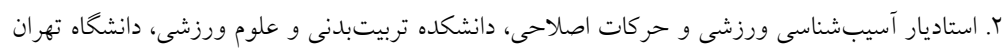

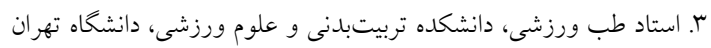

تاريخ بذيرش مقاله: IraF/IY/F

تاريخ دريافت مقاله: Iraץ/a/r|

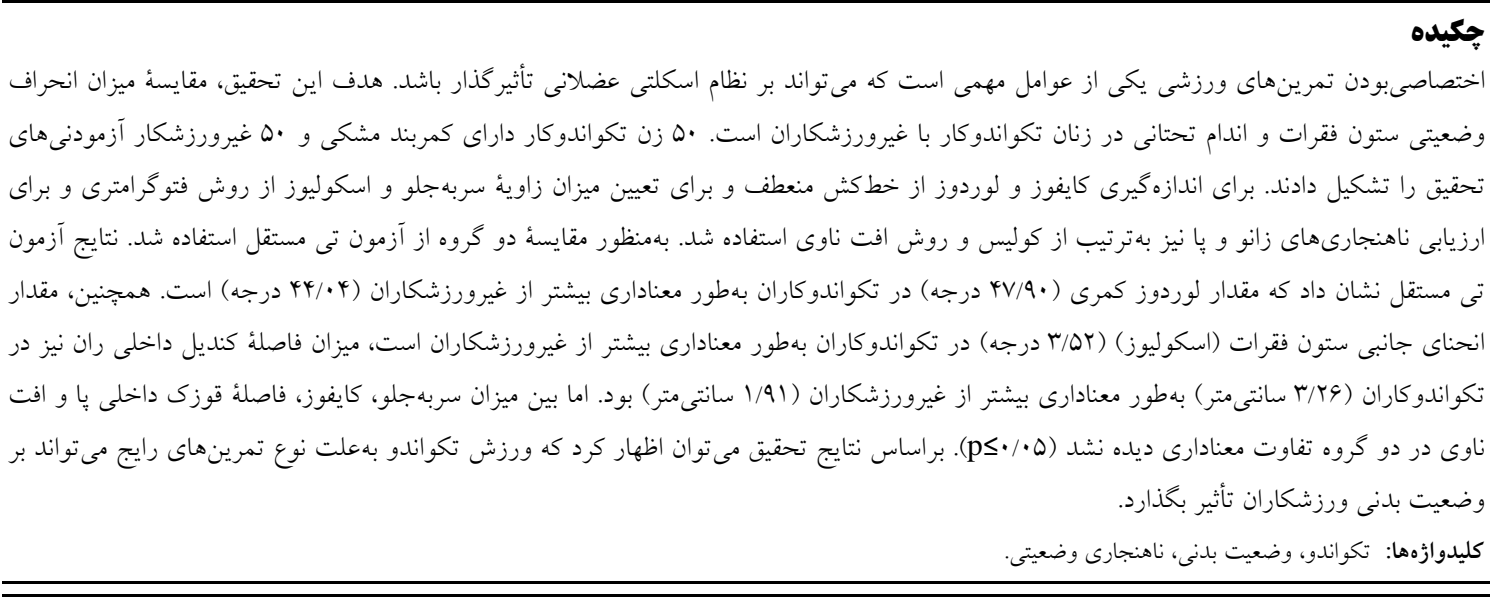

\title{
Comparison of posture in elite female taekwondo players and non-athletes
}

Hakimipour, $\mathbf{M}^{\mathbf{1}}$., Irandoost, $\mathbf{R}^{1}$., Minoonejad, $\mathbf{H}^{\mathbf{2}}$., Rajabi, $\mathbf{R}^{\mathbf{3}}$.

1. Master of Science, Sport Injuries and Corrective Exercises, Faculty of Physical Education and Sport Sciences, Tehran University, Iran

2. Assistant Professor, Sport Injuries and Corrective Exercises, Faculty of Physical Education and Sport Sciences, Tehran University, Iran

3. Full Professor, Sport Medicine, Faculty of Physical Education and Sport Sciences, Tehran University, Iran

\section{Abstract}

Specificity of physical exercises is one of the main factors which could affect musculoskeletal system. The purpose of this research is to make a comparison about postural abnormalities of the spine and lower limbs between female taekwondo athletes and non-athletes. Samples of current research were 50 female black-belt taekwondo athletes and 50 non-athletes. To measure kyphosis and lordosis, flexible ruler was used; also to determine the angle of forward head posture and scoliosis, photogrammetry was used, and to determine knee and foot deformities caliper and navicular drop methods were used respectively. To compare two groups, independent $t$ test was used. The results of independent $t$ test showed that amount of lumbar lordosis $\left(47.90^{\circ}\right)$ in taekwondo athletes is significantly higher than that of non-athletes $\left(44.04^{\circ}\right)$. Also amount of scoliosis $\left(3.52^{\circ}\right)$ in taekwondo athletes was significantly higher than that of non-athletes. Also distance of internal condyle ( $3 / 26 \mathrm{CM})$ of taekwondo athletes was significantly higher than that of nonathletes $(1 / 91 \mathrm{CM})(\mathrm{P} \leq 0.05)$. But no significant difference was observed between two groups in terms of forward head posture, kyphosis, distance of internal malleolus, and navicular drop. Based on the results of this research it is possible to express that taekwondo due to type of its common exercises and could have impact on posture of its athletes.

Keywords: Taekwondo, Posture, Malalignment.

*. m.hakimipoor@ut.ac.ir 


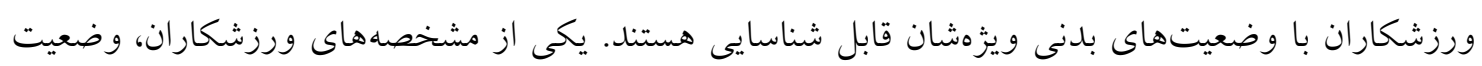

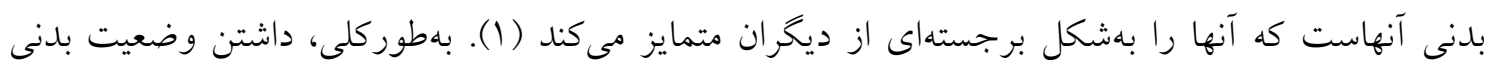
مناسب يكى از نيازهاى ضرورى انسان است. اين نياز در ورزشكاران اهميت بيشترى دارد، زيرا اجراى

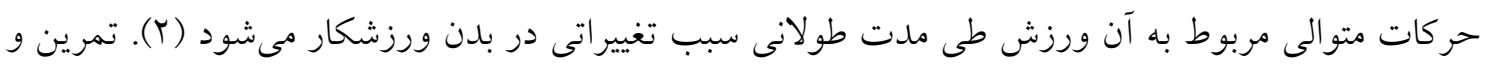

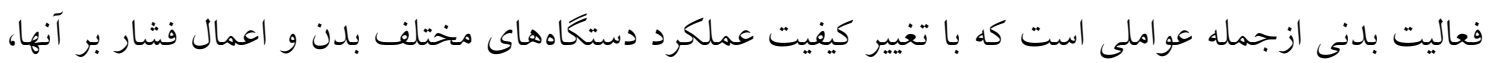
موجبات ايجاد تغييرات و سازكارى اين دستخاهها را فراهم مى آورند (r). بديدهُ سازكارى منفى دستخاه اسكلتى-عضلانى با نيازهاى حركتى و مهارتى ورزشكاران، ويزه ورزشكاران حرفهاى و قهرمانى، موضوع

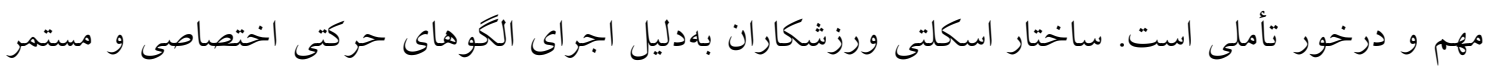
ممكن است دجار تغيير شود (Y). اختصاصىبودن تمرينات ورزشى يكى از عوامل مهمىاست كه مى تواند بر دستخاه اسكلتى-عضلانى تاثير كذار باشد و بسيارى از ناهنجارىهاى وضعيتى درنتيجهُ استفادهُ زياد از يكى يا

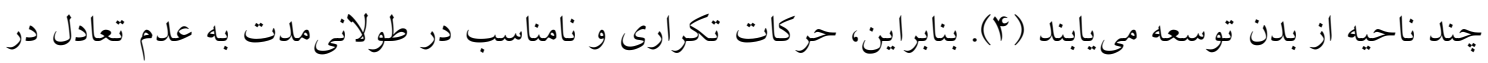
قدرت و استقامت عضلات مىانجامد و عضلات قادر به حفظ و نخهدارى قامت طبيعى بدن نخواهند بود. درنهايت، فرد در معرض اختلالهاى جسمانى ناشى از تغييرشكل طبيعى استخوانها و ناهنجارىهاى

وضعيتى قرار مى گيرد (ه).

ارتباط برخى ناهنجارىهاى وضعيتى با فعاليتها و تكنيكهاى مختص يكى رشتهٔ ورزشى گزارش شده است.

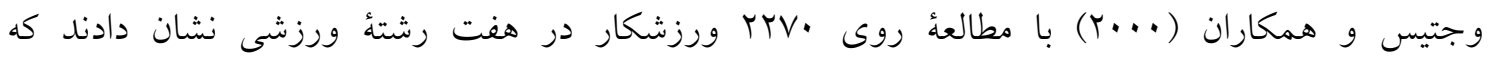
ناهنجارىهاى وضعيتى مانند كايفوز و لوردوز بهصورت معنادارى از غيرورزشكاران بيشتر است (Y). فورستر و همكاران (q. (Y) در تحقيقى به افزايش كايفوز و لوردوز در كوهنوردان حرفهاى نسبت به كوهنوردان

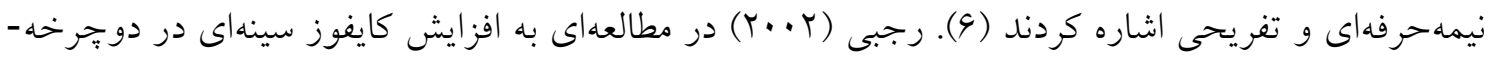
سواران گروههاى سنى مختلف نسبت به غيرورزشكاران همسان اشاره كرده است (V). قمرى و همكاران

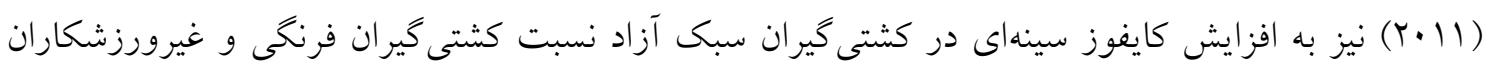

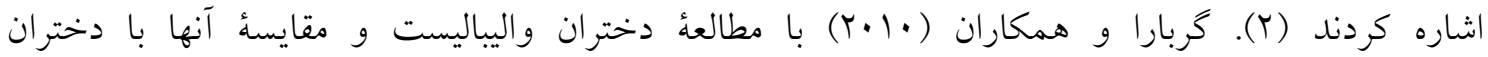
غيروززشكار همسن گروه مطالعه نشان دادند، تمرين، ويزه در جوانى ممكن است به بيدايش ناهنجارىهاى

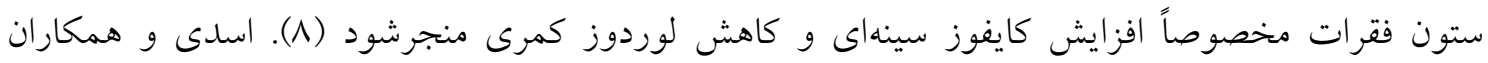

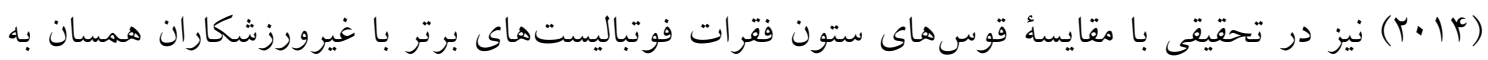

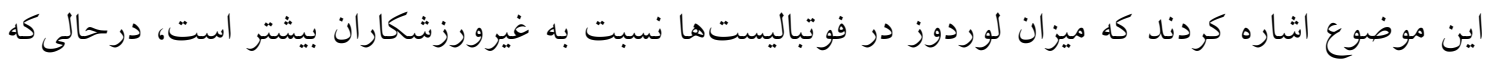

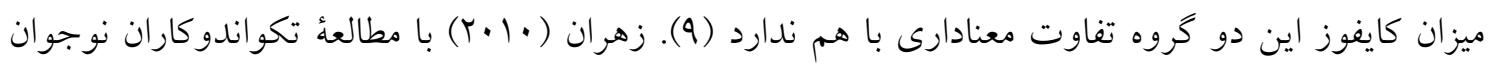
دختر و يسر، شايعترين ناهنجارى را در هردو گروه هايبرلوردوز گز ارش كرده است (• (1). البته اين تحقيق

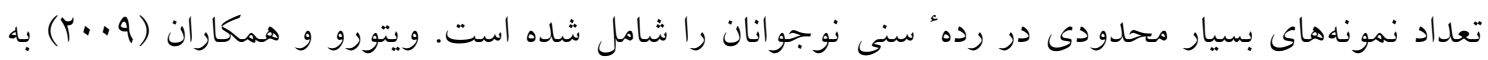


افزايش زانوى يرانتزى فوتباليستها در مقايسه با غيرورزشكاران اشاره كردهاند (11). همانطور كه كفته

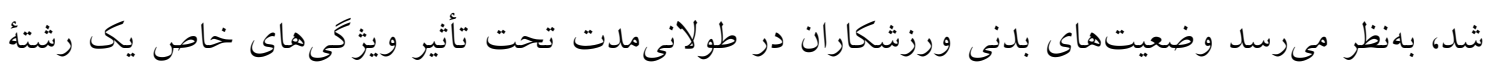
ورزشى تغيير كند،از اينرو، مطالعهُ حاضر، مقايسهُ ميزان سربهجلو، كايفوز سينهاى، لوردوز كمرى و اسكوليوز و ناهنجارىهاى زانو و كف پِيى تكواندو كاران و غيرورزشكاران است.

يزوهش حاضر ميدانى، مدل على -مقايسهاى و از نوع كاربردى است. جامعهُ آمارى تحقيق را دختران

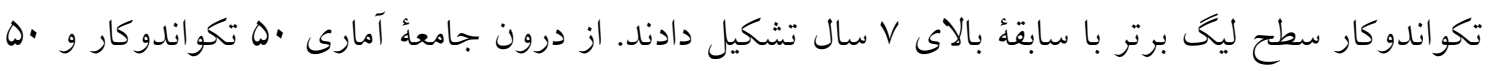

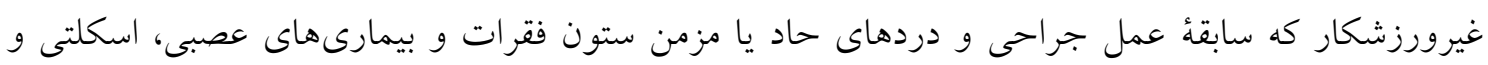

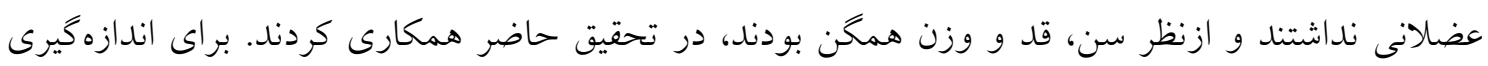
كايفوز سينهاى و لوردز كمرى از خط كش منعطف ساخت كشور ايران با نام بيستوله مارى استفاده شد. روايى

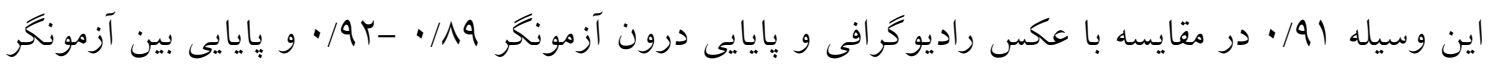

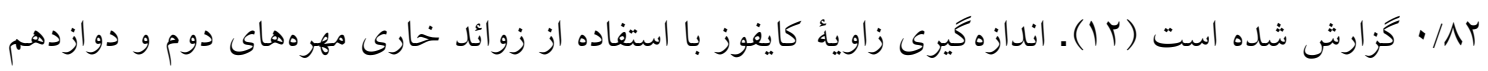

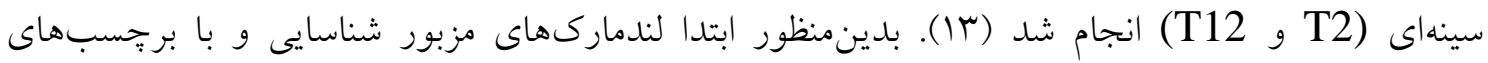

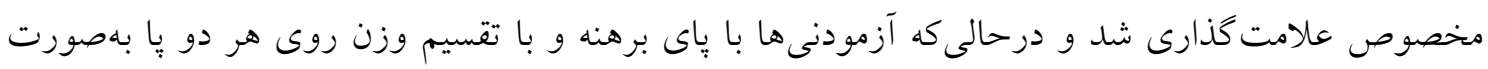

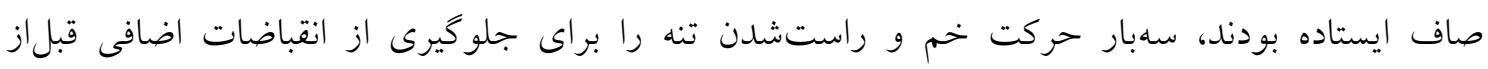
اندازه گيرى انجام دادند. سيس، خطكش منعطف روى ستون فقرات سينهاى فرد قرار داده شد تا شكل قوس را به خود بخيرد. آن كاه بِ إز ثابتشدن خط كش منعطف روى ستون فقرات، نقاطى از آن، كه در تماس با قسمت ميانى برجسب ها بود، علامت زده شد و بدون آنكه تغييرى در شكل خط كش منعطف صورت كيرد،

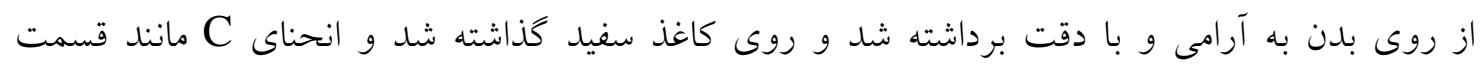
محدب آن، روى كاغذ ترسيم و نقاط T2 و T12 روى آن علامت زده شد. براى بهدست آوردن مقدى بهدار

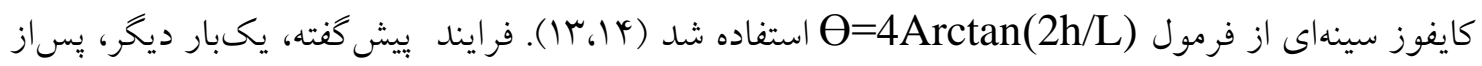
برداشتن برجسببها از روى نشانههاى استخوانى تكرار شد و ميانخين سه زاويةٔ بهدستآمده، به منزلهُ زاويه

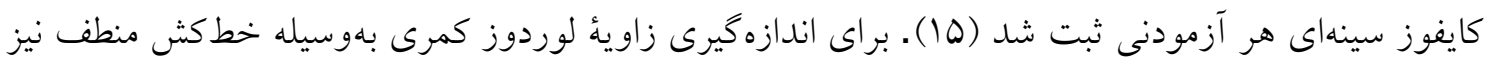

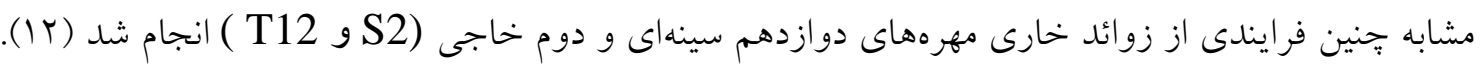

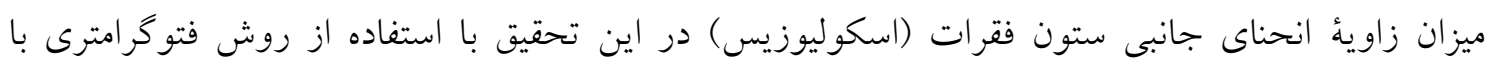

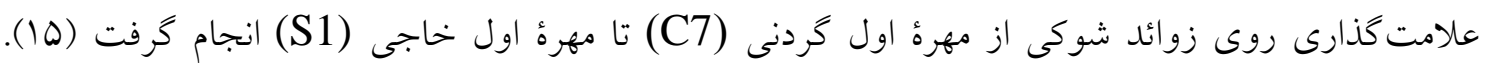

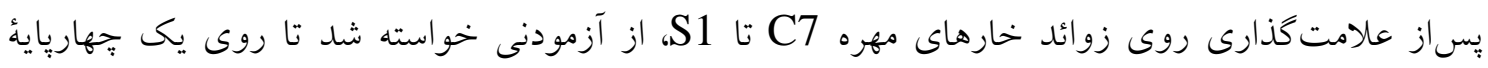
كو:جى با ارتفاع r ا سانتى متر بايستد. سبس، دوربين ديجيتال (Canon,model;Power shot A630)

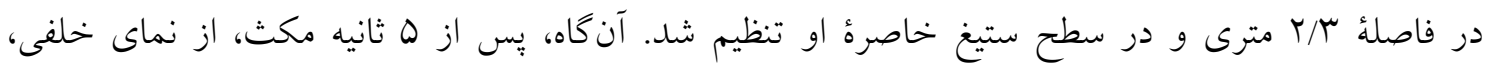
بهلطورى كه تمام ستون فقرات مشخص باشد، عكسبردارى انجام شد. هرعكس بِ بساز انتقال به رايانه، توسط 
نرمافزار فوكسيت ريدر' مورد تجزيه و تحليل قرار شد و زاويةٔ انحناى جانبى ستون فقرات براى هر فرد در

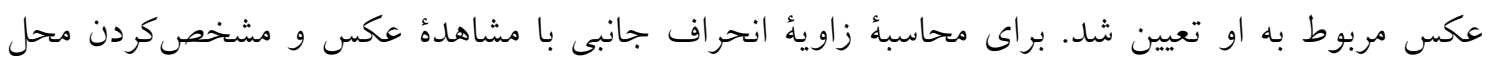

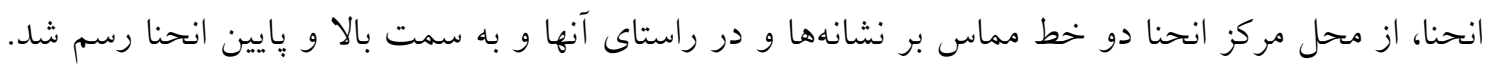
سبس، زاوئُ بين اين دو خط برحسب درجه با نرمافزار محاسبه شد (زاويه X). دراينحالت، زاوئ انحناى

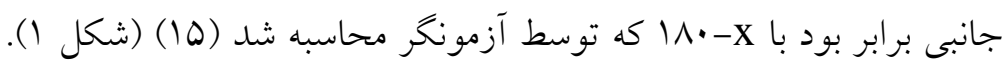

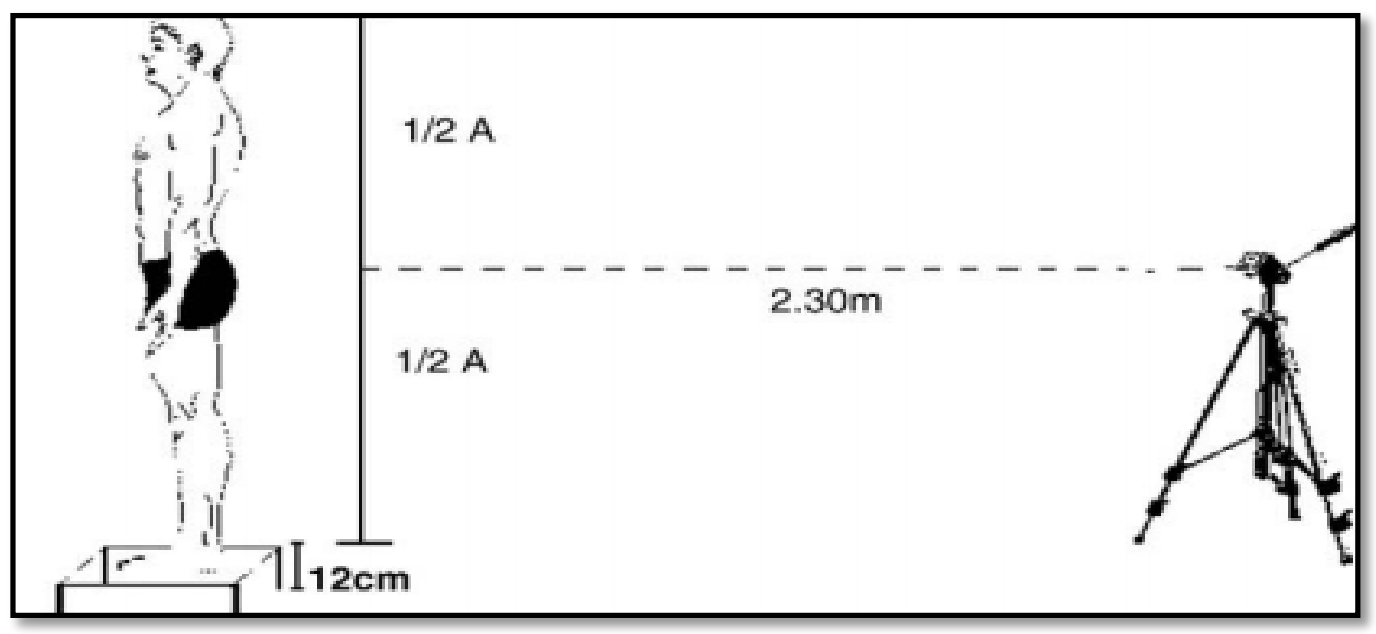

شكل ا. نحوة عكسبردارى از نماى بشتى براى محاسبة زاوية اسكوليوز

براى اندازهيرى زاوئُ سربهجلو بهوسيلة روش فتو گرامترى، ابتدا دو لندمارى؟ يعنى زائده؛ خارى مهره:

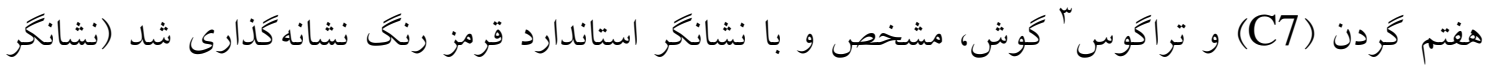

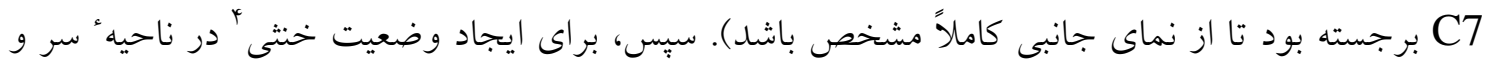

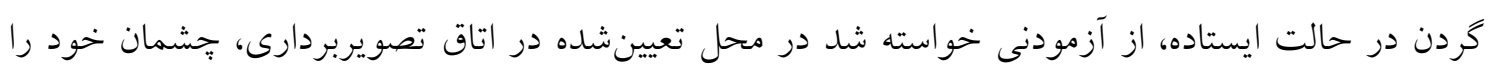

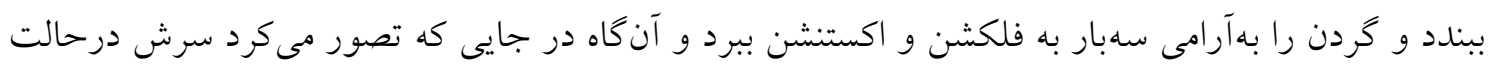

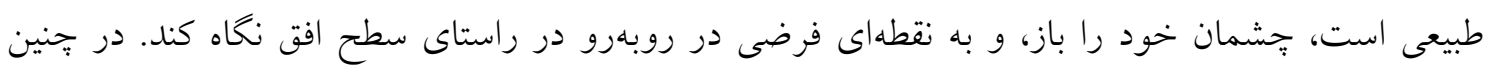

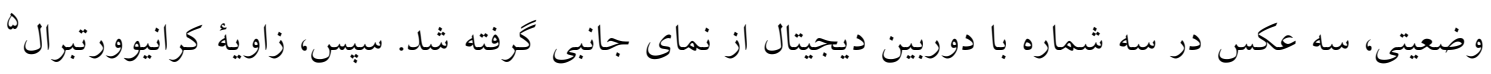
(زاويه بين خط رابط مهره هفتم گردن و تراگوس كوش با خط افقى) توسط نرمافزار ذكرشده تحت ارزيابى

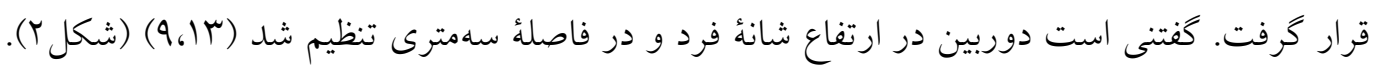




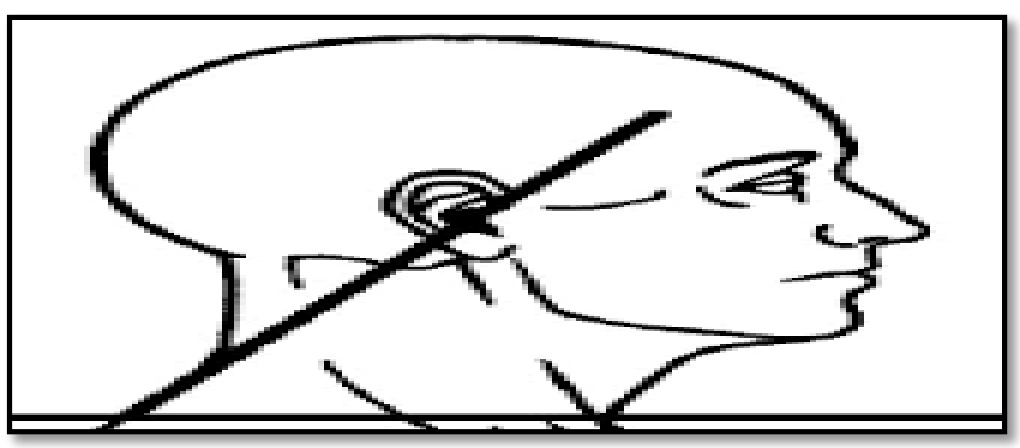

شكل r. نحوه محاسبة زاوية كرانيوور تبرال

براى اندازهيرى ناهنجارىهاى زانو ضربدرى و برانتزى، در اين تحقيق از اندازهگيرى فاصلهُ كنديلهاى

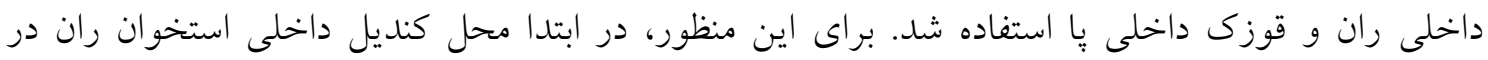
ناحيهُ زانو و همجنين قوزى داخلى استخوان درشتنى در هر دوياى آزمودنى توسط آزمونخر مشخص شد و و

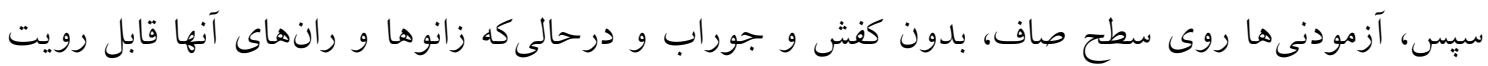

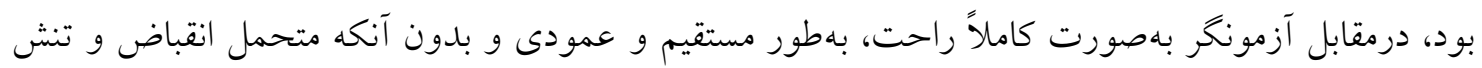

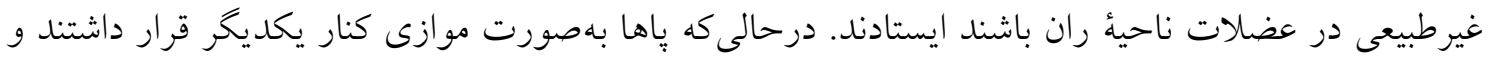
كنديل هاى داخلى ران و قوزكهاى داخلى آزمودنى در نزديكترين فاصلة نسبت به هم قرار داشتند و ران و و

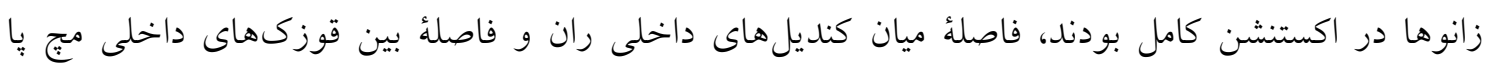
بهوسيله كوليس برحسب ميلىمتر اندازهيرى شد و اندازهيرىها دو بار تكرار شد و ميانخين آنها به منزلة

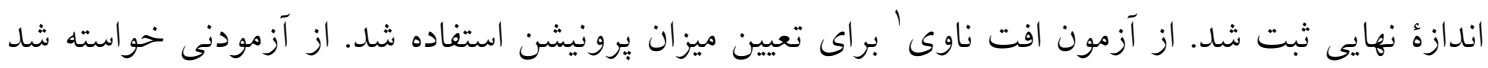
روى صندلى بنشيند، درحالى كه ران و زانوى او در وضعيت فلكشن •ه درجه، كف باهاى او روى زمين و

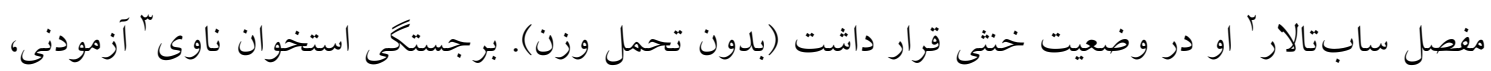

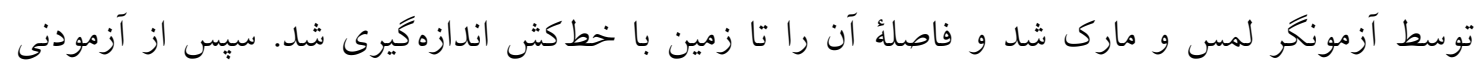

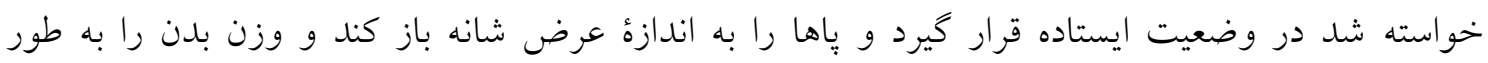
مساوى روى دو بِا قرار دهد (تحمل وزن). در اين حالت، فاصلة استخوان ناوى تا زمين دوبار اندازهگيرى

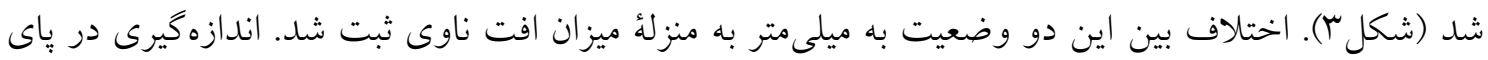

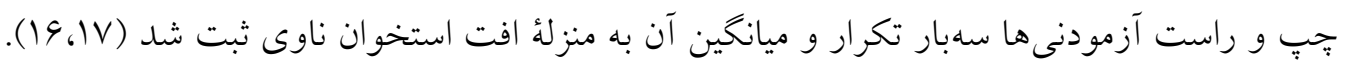




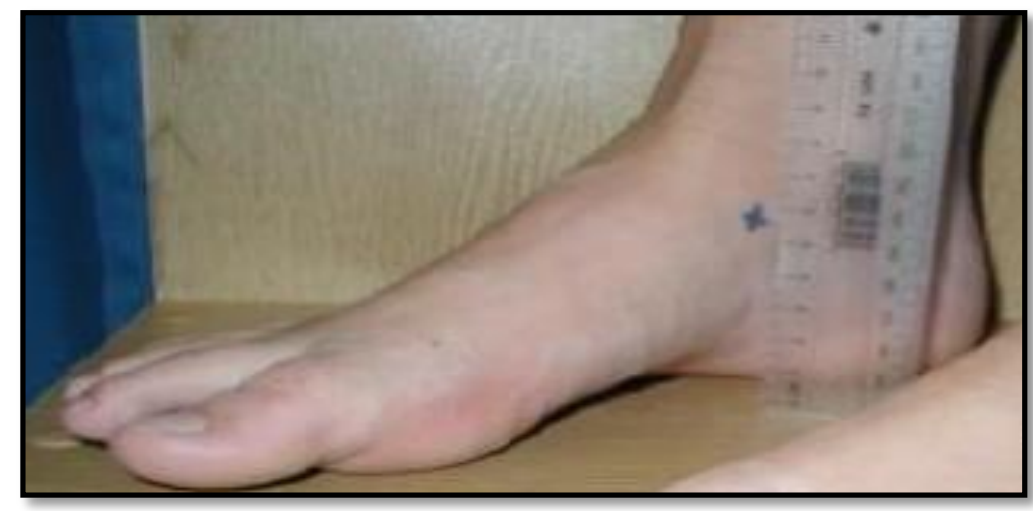

شكل r. اندازه گيرى افت ناوى

در جدول شماره ا، ميانخين و انحراف معيار اطلاعات توصيفى مربوط به اندازهگيرىهاى آنترويومتريك آزمودنى ها شامل قد، وزن و سن جهت شناخت بيشتر ويز كىهاى آزمودنى ها ارائه شده است.

\begin{tabular}{|c|c|c|c|}
\hline $\mathbf{P}$ & غيرورزشكار & تكو اندو كار & متغيرها \\
\hline$\cdot / T V$ & $r r / r q \pm 1 / r q$ & $r M / \Lambda \pm Y / M r$ & سن (سال) \\
\hline$\cdot / 91$ & $194 / T 4 \pm 9 / 19$ & $\mid G Y / Y Y \pm Q / V V$ & قد (سانتىمتر) \\
\hline.$/ 99$ & $\Delta \Delta / \wedge \pm V / \Delta \varphi$ & $\Delta Q / \wedge \pm V / \Delta \varphi$ & وزن (كيلو گرم) \\
\hline- & - & $\Lambda / Q G \pm 1 / \Delta r$ & سابقهُ ورزشى (سال) \\
\hline
\end{tabular}

جدول r نتايج آزمون تى مستقل را نشان مىدهد. همانطور كه ملاحظه مىشود، بين ميزان لوردوز كمرى (P=•••V)

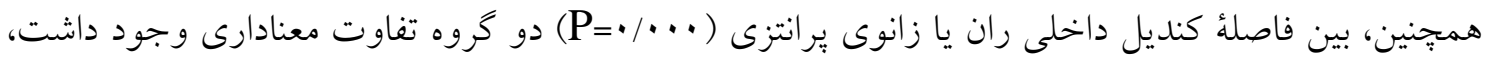

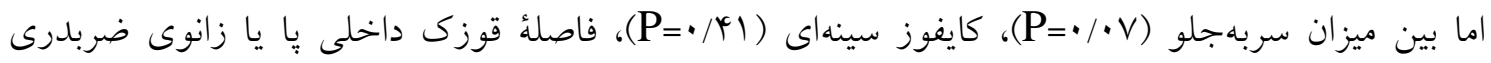

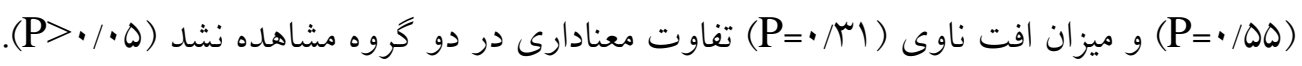


جدول r r نتايج آزمون t مستقل براى مقايسة متغيرهاى تحقيق بين دو گروه تكواندو كار و غيرورزشكار

\begin{tabular}{|c|c|c|c|c|c|}
\hline $\mathbf{P}$ & درجات آزادى & مقدار تى & ميانگين & 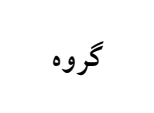 & 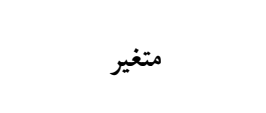 \\
\hline$\cdot / \cdot V$ & 91 & $-1 / \pi q$ & $\begin{array}{l}\text { KY/NTED/AT } \\
Y G / M T \pm Y / N T\end{array}$ & غيرورزشواندوار & سربهجلو (درجه) \\
\hline$\cdot / 4 \mid$ & 91 & $-1 / \cdot 1$ & $\begin{array}{l}r 4 / .9 \pm 9 / \mu r \\
r V / \Lambda \Lambda \pm V / \mu \Lambda\end{array}$ & غيروز تكو اندو كار & كايفوز (درجه) \\
\hline$\cdot / \cdot r * *$ & 91 & $r / 9$. & $\begin{array}{l}\Psi V / Q \cdot \pm \Lambda / \Lambda Q \\
F \psi / \cdot \Psi \pm \Delta / q T\end{array}$ & غيرورزشكار & لوردوز ( درجه) \\
\hline$\cdot / \cdot 1 *$ & 91 & $1 / 9 \Lambda$ & $\begin{array}{l}r / Y q \pm Y / 9 V \\
|/ 9| \pm r / r \mid\end{array}$ & غيرورزشكار & اسكوليوز (درجه) \\
\hline$\cdot / \cdot 1 *$ & 91 & $r / 94$ & $\begin{array}{l}Y / V \Delta \pm 1 / 99 \\
1 / \cdot \Lambda \pm 1 / 91\end{array}$ & غيروز تشو اندو كار & فاصلة كنديل هاى داخلى \\
\hline$\cdot / \Delta \Delta$ & 91 & $-\cdot 109$ & $\begin{array}{l}r / Y q \pm r / 9 V \\
|/ 9| \pm r / r \mid\end{array}$ & غيرورزشكار & 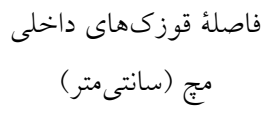 \\
\hline$\cdot / \mu 1$ & 91 & $1 / \cdot 1$ & $\begin{array}{l}Q / \Lambda \pm \Lambda / r \\
V / \Lambda \pm r / r\end{array}$ & غيروز تكواندو كار & افت ناوى (ميلىمتر) \\
\hline
\end{tabular}

$\mathrm{P}<\cdot / \cdot \Delta$ معنى مارى در سطح

هدف يُزوهش حاضر، مقايسُٔ ميزان انحرافات وضعيتى ستون فقرات و اندام تحتانى در زنان تكواندوكار با

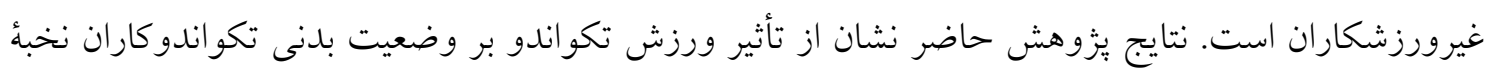

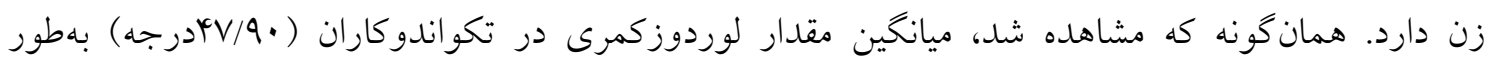

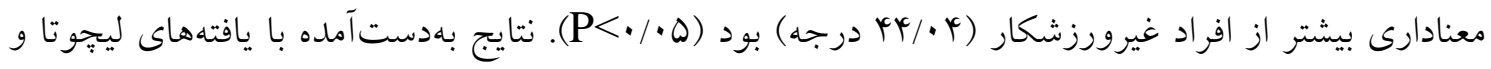
همكاران (11) جهتدار و مختص رشتههاى ورزشى را بر شكل قوسهاى ستون فقرات كه محققان ديخر گزارش كردهاند

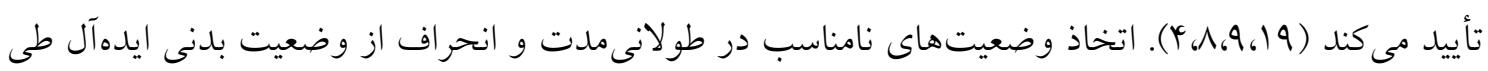
زمان با اثر بر نظام عضلانى اسكلتى مى تواند موجب ايجاد تغييراتى در وضعيت بدنى شود (V، (). مشخص شده است تمرينات اختصاصى ورزشهاى مختلف مىتوانند سبب تغييرات وضعيتى متناسب با رشته ورزشى، بهويزه در ورزشكاران نوجوان و جوان شوند (·r). با توجه به اينكه بيشتر ضربههاى باى تكواندو شامل فلكشن ران و اكستنشن زانو هستند، درنتيجأ استفادهُ مداوم از عضلات جهارسر و همجنين سوئز

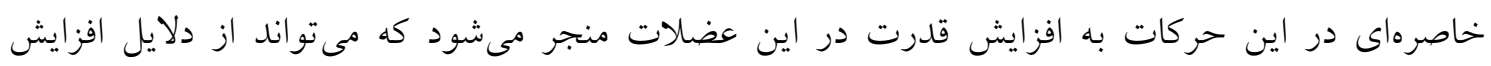
لوردوز كمرى در تكواندوكاران نسبت به غيرورزشكاران باشد (Y). اسدى و همكاران نشان دادند كه در فوتباليستها افزايش قدرت عضلات فلكسور ران مىتواند نيروى لازم را براى جرخش قدامى بيشازحد

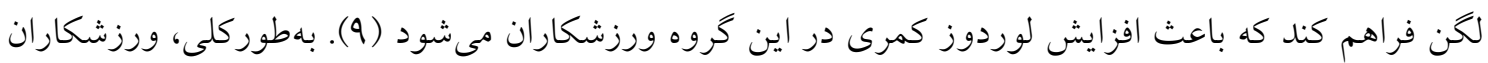


تكواندو تأكيد زيادى بر تقويت عضلات يشت' و پِا دارند (•) كه احتمالاً مىتواند يكى از دلايل بروز لو لودوز كمرى باشد.

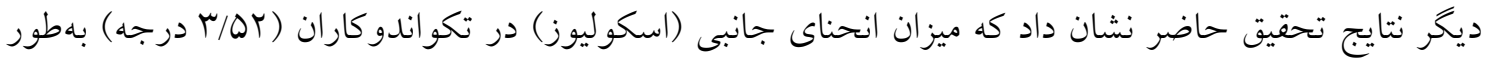

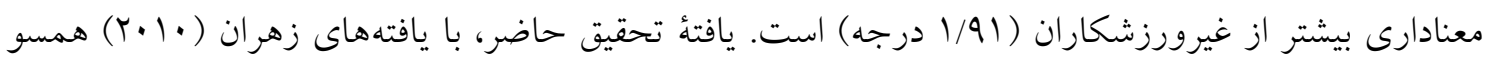
است كه گزارش داد حدود ها درصد از تكواندوكاران داراى اسكوليوز هستند (••). توسعه و رشد ستون

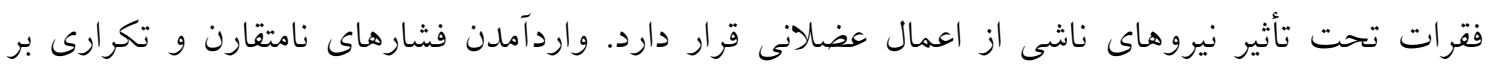
ستون فقرات درنتيجه حركات ورزشى مختلف بهويزه در ورزشكاران قبلاز سن بلوغ يكى از دلايل اصلى بروز اسكوليوز است (Tr) و ازآنجايى كه ورزشكاران براى رسيدن به سطوح بالاى عملكردى غالباً فعاليت

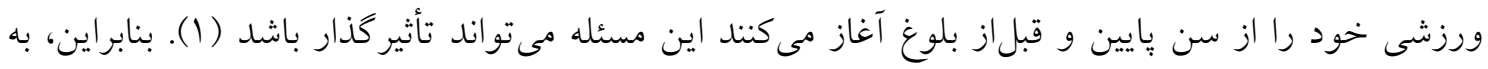

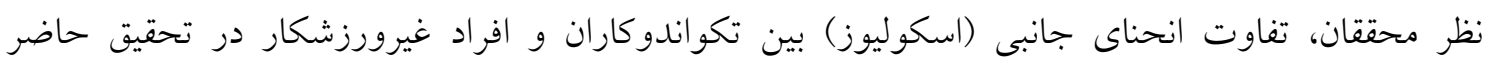

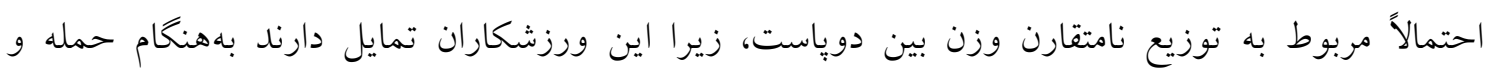

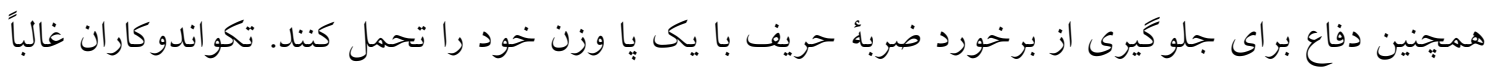
براى اجراى تكنيكهاى اين رشته غالباً از يا و دست برتر خود استفاده مى كنند (Y) (Y). استفادهُ مكرر و و يكىطرفه از اندامهاى بدن حين تمرين و مسابقه نيز مىتواند از دلايل احتمالى افزايش اسكوليوز در اين كروه

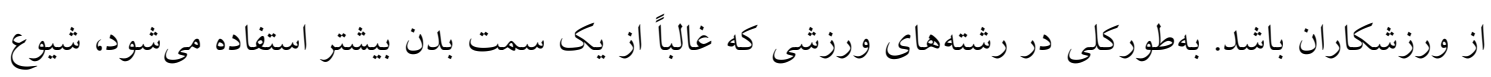

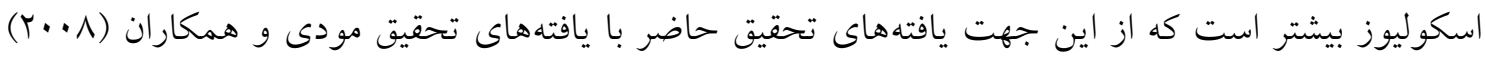

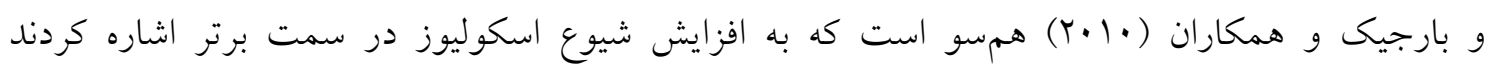

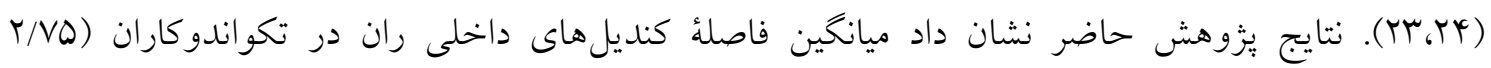

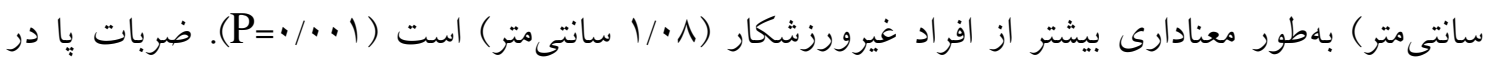

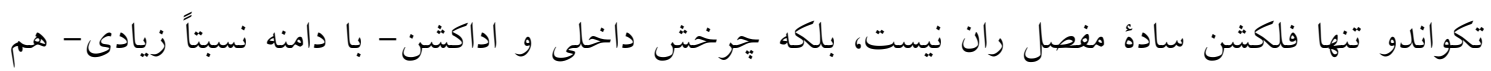
درحين اين ضربات در مفصل ران رخ مىدهد ( (Y). تكرار بسيار زياد ضربات يا در تكواندو احتمالاً مى تواند

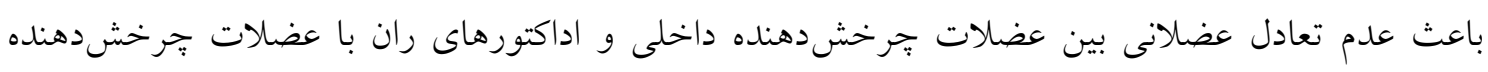

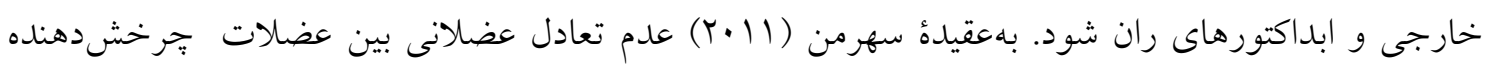
داخلى و اداكتورهاى ران با عضلات جرخشدهنده خارجى و ابداكتورهاى ران مهمترين علت بروز ناهنجارى زانوى يرانتزى مىباشد (TQ).

\section{نتيجهيرى}

بلهوركلى، نتايج تحقيق حاضر نشان داد كه ورزش تكواندو بهعلت نوع تمرينات و فعاليتهاى رايج در آن

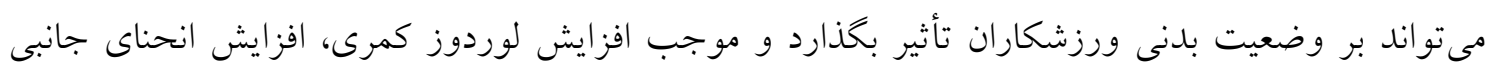

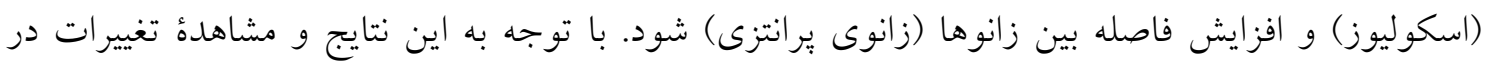

1.Back Muscles 


$$
\begin{aligned}
& \text { وضعيت بلنى تكواندو كاران، بـه كروه يزشكى -ورزشى تيمهاى تكواندو بيشنهاد ميىشود هر كونه تغيير در } \\
& \text { وضعيت بلنى تكواندوكاران، بخصوص افزايش لوردوزى كمرى، ايتجاد اسكوليوز و افزايش فاصله بين } \\
& \text { كونديل هاى داخلى ران (زانوى يرانتزى شدن)، ورزشكاران را بررسى كنند و با غربال گرى مناسب و بهموقع }
\end{aligned}
$$

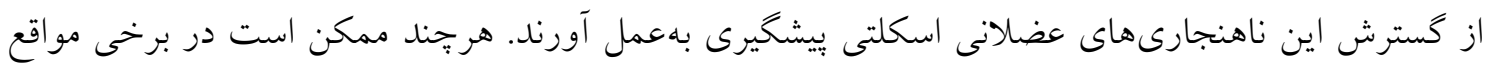

$$
\begin{aligned}
& \text { اين ناهنجارىهاى ساز گارشده با رشتهُ ورزشى، مزيتى مكانيكى را در آن رشته بهدنبال داشته باشد كه اين } \\
& \text { موضوع به بررسى و مطالعهُ بيشتر نياز دارد. }
\end{aligned}
$$

1. Wodecki, P., Guigui, P., Hanotel, M.C., Cardinne, L., Deburge, A. (2002) .Sagittal alignment of the spine: comparison between soccer players and subjects without sport activities.Revue de chirurgie orthopedique et reparatrice de l'appareil moteur. 88(4): 328-36.

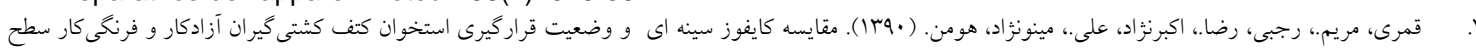

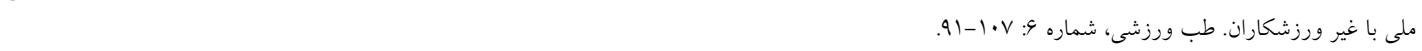

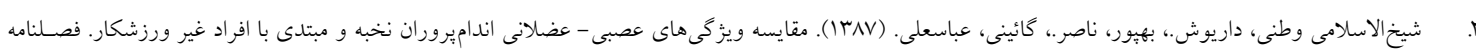

4. Wojtys, E.M., Ashton-Miller, J.A., Huston, L.J., Moga, P.J. (2000). The association between athletic training time and the sagittal curvature of the immature spine. The American Journal of Sports Medicine. 28(4): 490-8.

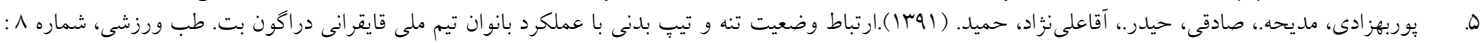

6. Förster, R., Penka, G., Bösl, T., Schöffl, V. (2009).Climber's back-form and mobility of the thoracolumbar spine leading to postural adaptations in male high ability rock climbers. International Journal of Sports Medicine. 30(1): 53-9.

7. Rajabi, R. (2002). An investigation in two sagittal thoracic curvature (sport related postural mal-aligment) in cyclist and non-cyclist. PhD Dissertation ,University of Manchester.

8. Grabara, M., Hadzik, A. (2009). Postural variables in girls practicing volleyball. Biomedical Human Kinetics. 1: 6771.

9. Asadi, M., Nourasteh, A., Daneshmandi, H. (2014). Comparison of spinal column curvatures between master football players and their non-athletes peers. International Journal of Sport Studies. 4(3): 338-42.

10. Zahran, A.S. (2010). A comparative study of some biological characteristics and posture deflections of the egyptian junior national taekwondo team. World Journal of Sport Sciences. 3:1026-33.

11. Witvrouw, E., Danneels, L., Thijsm Y., Cambier, D., Bellemans, J. (2009). Does soccer participation lead to genu varum?. Knee Surgery, Sports Traumatology, Arthroscopy. 17(4): 422-7.

12. Seidi, F., Rajabi, R., Ebrahimi T.S, Tavanai, A., Moussavi, S. (2009). The Iranian flexible ruler reliability and validity in lumbar lordosis measurement. World Journal of Sport Sciences. 2(2): 95-9.

13. Hinman, M.R. (2004).Comparison of thoracic kyphosis and postural stiffness in younger and older women. The Spine Journal. 4(4): 413-7.

14. Teixeira, F., Carvalho, G. (2007). Reliability and validity of thoracic kyphosis measurements using flexicurve method. Brazilian Journal of Physical Therapy. 11(3):173-7.

15. 15.Saad, K.R., Colombo, A.S., João, S.M. (2009). Reliability and validity of the photogrammetry for scoliosis evaluation: a cross-sectional prospective study. Journal of Manipulative and Physiological Therapeutics. 32(6): 423-30.

16. Brody, D. ( 1982). Techniques in the evaluation and treatment of the injured runner. The Orthopedic Clinics of North America.13(3): 541-58.

17. Cote, K.P., Brunet, M.E., Gansneder, B.M., Shultz, S.J.(2005). Effects of pronated and supinated foot postures on static and dynamic postural stability. Journal of Athletic Training. 40(1): 41-6.

18. Lichota, M., Plandowska, M., Mil, P. (2011). The shape of anterior-posterior curvatures of the spine in athletes practising selected sports. Polish Journal of Sport and Tourism. 18(2): 112-6.

19. Cavanaugh, J.T., Guskiewicz, K.M., Giuliani, C., Marshall, S., Mercer, V., Stergiou, N. (2005). Detecting altered postural control after cerebral concussion in athletes with normal postural stability. British Journal of Sports Medicine. 39(11): 805-11.

20. Gautier, G., Thouvarecq, R., Larue, J. (2008). Influence of experience on postural control: effect of expertise in gymnastics. Journal of Motor Behavior. 40(5): 400-8.

21. Kim, Y.K., Kim, Y.H., Shin, S.J. (2011). Inter-joint coordination in producing kicking velocity of Taekwondo kicks. Journal of Sport Science and Medicine.10: 31-8.

22. Aebi, M. (2005). The adult scoliosis. European Spine journal. 14: 925-48.

23. Barczyk-Pawelec, K., Bankosz, Z., Derlich, M. (2012). Body postures and asymmetries in frontal and transverse planes in the trunk area in table tennis players. Biology of Sport. 29(2): 129-34.

24. Modi, H., Srinivasalu, S., Smehta, S., Yang, J.H., Song, H.R., Suh, S.W. (2008). Muscle imbalance in volleyball players initiates scoliosis in immature spines: a Screening Analysis. Asian Spine Journal. 2(1): 38-43

25. Sahrmann, S.H. (2010). Movement system impairment syndromes of the extremities, cervical and thoracic spines. Elsevier Health Sciences. 